\title{
Which Polishing Method is Effective for Coffee Stains? - An in Vitro Study of Surface Roughness and Color Change
}

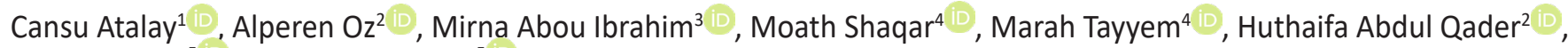 \\ Ali Tugrul Gur ${ }^{5}$, Guliz Nigar Guncu ${ }^{5}$ \\ ${ }^{1}$ Department of Restorative Dentistry, School of Dentistry, Hacettepe University, Ankara, Turkey. \\ ${ }^{2}$ School of Dentistry, Hacettepe University, Ankara, Turkey. \\ ${ }^{3}$ School of Dentistry, Beirut Arab University, Beirut, Lebanon, Beirut. \\ ${ }^{4}$ School of Dentistry, The University of Jordan, Amman, Jordan. \\ ${ }^{5}$ Department of Periodontology, School of Dentistry, Hacettepe University, Ankara, Turkey. \\ Correspondence Author: Cansu Atalay \\ E-mail: cansuatalaydr@gmail.com, cansugulcan@hacettepe.edu.tr \\ Received: 15.02.2021 Accepted: 10.05.2021
}

\begin{abstract}
Objective: To assess the effects of three different polishing protocols on the surface roughness and color change of the enamel and compare the results with the enamel specimens exposed to coffee.

Methods: Seventy-two bovine enamel specimens were randomly divided into two groups-Group I: only polishing, Group II: immersion in coffee solution and polishing-which were then subdivided into three groups according to polishing procedures as follows: polishing with rubber cup and Pumice Flour (PF), polishing with rubber cup and Prophy Paste (PP), polishing with Air Abrasion (AA). Surface roughness (Ra) and tooth color were assessed using a surface profilometer and a digital spectrophotometer. The color change was determined by the CIE L*a*b* system. One specimen from each group was also examined by SEM. Statistical analyses were performed by GraphPad software. Kruskal-Wallis and Friedman tests were used for multiple comparisons between-groups and in-groups, respectively.

Results: At baseline measurements, no significant differences were found among groups in terms of roughness and color values ( $p>0.05$ ). In Group I, surface roughness values and color change were similar after polishing ( $p=0.393, p=0.093$, respectively). In Group II, post-polishing Ra values were significantly increased in all groups $(\mathrm{p}<0.05)$ and the highest $\Delta E$ value was detected in PP group.

Conclusion: Following coffee immersion, enamel surfaces become rougher in all polishing protocols and the roughest surface was in PF group. In all study groups visible clinical success was achieved in terms of color; therefore, dental clinicians should prefer PP in clinical practice due to the less abrasive and sufficient color change properties.

Keywords: surface roughness, color change, polishing protocols, enamel
\end{abstract}

\section{INTRODUCTION}

Clinicians remove plaque, calculus and stain from tooth surfaces by scaling, cleaning and polishing (1). On the other hand, the mechanical method most frequently used by individuals to control plaque accumulation is tooth brushing. However, it cannot completely and effectively remove all dental plaques, especially when not done regularly. In modern societies, people's desire to have clean teeth is increasing day by day, and many people apply to dentists once in 3-6 months for a professional dental cleaning (2).

The common two methods that dentists use for oral prophylaxis are rubber cup and air-polishing. The rubber cup procedure is the application of some agents to the tooth surfaces with a rotating rubber cup or rotating bristle brushes. One of the most commonly used agents during prophylaxis procedures is pumice-water mixture applied to the tooth surface with the help of brushes and rubber cups attached to rotating tools. As an alternative to this agent, commercial prophylaxis pastes have been frequently used by dentists in recent years (3). In air-polishing procedure, air and water pressure are mixed with an abrasive powder, so the remaining external stains are removed. Some studies have suggested that this method is more effective, useful and requires less chair time than polishing procedures with rubber cups $(4,5)$.

Although enamel tissue shows a clinically smooth surface, there are some microscopically detected structures on its surface. Polishing methods have been suggested to be clinically safe. However, they can cause scratches on the enamel surface or create rough surfaces, which can result in faster deposition of biofilm products. Some studies reported 
no morphological changes $(6,7)$, while others reported only minimal changes in the enamel surface $(8,9)$.

Due to the accumulation of plaque and surface stains, the external discoloration is closely related to hygiene, smoking habits and diet. Some studies have shown the coloring effect of staining solutions consumed frequently, such as tea and coffee $(10,11)$. Coffee is one of the most frequently consumed and colored drinks in daily life. Moreover, the reason for the coloring effect of coffee is shown to have a dark color and an acidic $\mathrm{pH}$ value (11). Enamel, the outermost layer of teeth, is open to attack, so staining of the enamel can cause demineralization and erosion $(12,13)$. According to coffee manufacturers, the consumption of a mug of coffee takes an average of 15 minutes, and a coffee consumer consumes 2 cups of coffee three times a day. Therefore, keeping the samples 24 hours in coffee corresponds to monthly coffee consumption in vitro studies (10).

One of the important goals of today's modern esthetic dentistry is to ensure the continuity of dental esthetics by preserving the natural tooth color (14). Each individual's natural tooth color is unique and is affected by various factors. Some external stains can be partially or completely removed by brushing teeth with toothpaste or professional prophylaxis (15). Moreover, there are both positive and negative aspects of every treatment. The most common problems faced by dentists with polishing methods in clinical routine are that patients may have a feeling of roughness in their teeth after the procedure or that unwanted coloring is frequently repeated following previous polishing treatment.

In the light of all this information, the purpose of this in vitro study was to assess the effect of three different polishing protocols - pumice flour (PF), prophy paste (PP) and air abrasion (AA) - on the surface roughness and color change of the enamel and compare the results with the enamel specimens exposed to coffee solution followed by polishing protocols. The tested null hypotheses were as follows: [1] there would be no difference between the tested polishing systems in terms of the effect on enamel surface roughness and color change [2] different polishing systems would have no influence on the roughness of the enamel surface and the color change after exposure to coffee.

\section{MATERIALS AND METHODS}

\subsection{Specimen Preparation}

A total of thirty-six sound bovine incisors were stored at $100 \%$ moisture containing $10 \%$ formalin before usage. Calculus and soft tissue deposits were cleaned using a hand scaler. The teeth were sectioned buccolingually using a watercooled diamond cutting disc $(n=72)$, and then all teeth were mounted on a self-hardening acrylic resin (Meliodent, Heraeus/Kulzer, Hanau, Germany) block with the buccal surface exposed. The sample surfaces were first grounded with 600-grit and then 1000-grit silicon carbide papers under running water for $10 \mathrm{~s}$ on a polishing machine (LabPol 21,
Struers, Ballerup, Denmark) and kept in deionized water at 37 ${ }^{\circ} \mathrm{C}$. Using a power of $80 \%$, the sample calculation indicated the need for approximately 12 teeth for each group in order to determine a difference of $25 \%$ among the study groups.

\subsection{Groups and Applications}

The color and surface roughness (Ra) of all teeth were assessed at baseline prior to the polishing procedures using a surface profilometer (Perthometer, M1 Mahr, Göttingen, Germany) and a spectrophotometer (VITA Easyshade, VITA Zahnfabrik, Bad Sackingen, Germany), respectively. Then, the teeth were categorized into two groups having 36 teeth in each. The specimens were distributed to the groups paying attention to the $\mathrm{L}^{*}, \mathrm{a}^{*}$ and $\mathrm{b} *$ initial parameters. While Group I was only subjected to polishing procedures, Group II was immersed in coffee solution (Nescafé Classic, Nestlé, Vevey, Switzerland) and then polished. These groups were also subdivided into three groups according to polishing procedures as follows $(n=12)$ :

Group PF: The samples were polished for $15 \mathrm{~s}$ with a rubber cup and pumice flour (Isler Dental; Ankara, Turkey) attached to the low-speed contra-angle handpiece in a circular motion. The rpm value applied for speed was a steady slow pace of $2500 \mathrm{rpm}$.

Group PP: The samples were polished for $15 \mathrm{~s}$ with a rubber cup and polishing paste (Deepak Products, Inc.; Keystone Europe LLC, Netherlands) attached to the low-speed contraangle handpiece in a circular motion. The rpm value applied for speed was a steady slow pace of $2500 \mathrm{rpm}$.

Group AA: The samples were polished for $15 \mathrm{~s}$ with an air polisher (Prophy-Tech; Benlioglu Dental Inc., Ankara, Turkey) using sodium bicarbonate powder. Air setting 20 psi. The tip of the air polisher was set at a $90^{\circ}$ angle to the tooth surface when the distance was held constant at $6 \mathrm{~mm}$.

In practice, all polishing procedures were performed by the same operator.

\subsection{Coffee Immersion}

The coffee solution was prepared by pouring $15 \mathrm{~g}$ of coffee powder (Nescafe ${ }^{\circ}$ Classic, Nestle SA, Vevey, Switzerland) into $500 \mathrm{~mL}$ of boiling distilled water. After the solution has been stirred for 10 minutes, it was filtered through filter paper. The immersion time was 48 hours.

\subsection{Measurement of Surface Roughness}

The average surface roughness ( $\mathrm{Ra} ; \mu \mathrm{m}$ ) was measured with a Surface Profilometer using a tracing length of $1.25 \mathrm{~mm}$ and a cutoff of $0.25 \mathrm{~mm}$ to maximize filtration surface waviness, and a measuring speed of $0.5 \mathrm{~mm} / \mathrm{s}$. In each specimen, measurements were made three times in different directions and at different locations by turning it around. The roughness values were recorded by taking the average of the obtained values. The performance of the device was controlled by 
using a calibration block after each specimen. Baseline measurements were recorded for all samples before they were divided into groups. For Group I, surface roughness measurements were recorded as post-polishing; for Group II, Ra was recorded as post-immersion and post-polishing.

\subsection{Measurement of Color Values}

Color values were recorded in sequence using a digital spectrophotometer. Following baseline measurements; for Group I, color value measurements were recorded as post-polishing; for Group II, color value measurements were recorded as post-immersion and post-polishing. The spectrophotometer measured the tooth color based on the CIEL*a*b* color space system, which allows the color to be determined in three-dimensional space.

The color difference $(\Delta \mathrm{E})$ between the color coordinates was calculated by applying the formula $\Delta \mathrm{E}=\left[(\Delta \mathrm{L})^{2}+\right.$ $\left.(\Delta a)^{2}+(\Delta b)^{2}\right]^{1 / 2}$. Three measurements were taken with the spectrophotometer at the center of each sample. So, the instrument automatically averaged three readings for each sample, which were then used for overall data analysis. The device was also calibrated before each measurement.

\subsection{Scanning Electron Microscopic Analysis}

One representative specimen from each group was prepared for SEM evaluation. For the decontamination of the samples, a soaking procedure was performed in $10 \%$ neutral buffered formalin solution for 8 hours. The specimens were fixed on metal stubs and were then gold-sputtered (one cycle of 120 s) under a vacuum atmosphere in a sputtering device (MED 010, Balzers Union, Balzers, Liechtenstein). The surfaces were examined by scanning electron microscopy (Tescan GAIA 3) to examine the effect of polishing systems.

\subsection{Statistical Analysis}

Statistical analyses were performed by GraphPad Prism 8.2.1 for Windows (GraphPad Software, San Diego, California). In addition to the descriptive analysis, data were analyzed using non-parametric tests, alpha=0.05. Multiple comparisons between-groups and in-groups were performed using Kruskal-Wallis and Friedman tests, respectively. For pairwise comparisons, Wilcoxon matched pairs signed rank test was used in - groups and Mann Whitney-U test was used in between - groups.

\section{RESULTS}

\subsection{Surface Roughness}

At baseline measurements, no significant differences were found among treatment groups in terms of roughness in both Group I and II ( $p=0.836, p=0.530$, respectively). Medians (min-max) of surface roughness values are presented in Table 1 for Group I and in Table 2 for Group II.
Table 1. Comparison of the Surface Roughness Within and Among Different Polishing Protocols at baseline and Post-polishing in Group I.

\begin{tabular}{|c|c|c|c|}
\hline \multirow[t]{2}{*}{ Subgroups } & Baseline Ra & Post-polishing Ra & \multirow[t]{2}{*}{$p$} \\
\hline & $\begin{array}{l}\text { Median } \\
\text { (min-max) }\end{array}$ & \begin{tabular}{|l} 
Median \\
(min-max)
\end{tabular} & \\
\hline Pumice flour & $\begin{array}{l}0.232 \\
(0.146-0.442) \\
\end{array}$ & \begin{tabular}{|l|}
0.192 \\
$(0.156-0.246)$ \\
\end{tabular} & $0.016^{*}$ \\
\hline Prophy paste & $\begin{array}{l}0.211 \\
(0.115-0.280) \\
\end{array}$ & \begin{tabular}{|l|}
0.204 \\
$(0.128-0.266)$ \\
\end{tabular} & 0.102 \\
\hline Air abrasion & \begin{tabular}{|l|}
0.213 \\
$(0.140-0.448)$
\end{tabular} & $\begin{array}{l}0.189 \\
(0.137-0.299)\end{array}$ & 0.176 \\
\hline$p$ & 0.836 & 0.393 & \\
\hline
\end{tabular}

* significantly different from baseline ( $p<0.05)$.

Table 2. Comparison of the Surface Roughness Within and Among Different Polishing Protocols at Baseline, Post-Immersion and PostPolishing in Group II.

\begin{tabular}{|l|l|l|l|l|}
\hline Subgroups & Baseline Ra & $\begin{array}{l}\text { Post- } \\
\text { immersion Ra }\end{array}$ & $\begin{array}{l}\text { Post-polishing } \\
\text { Ra }\end{array}$ & $\mathbf{p}$ \\
\cline { 2 - 4 } & $\begin{array}{l}\text { Median } \\
\text { (min-max) }\end{array}$ & $\begin{array}{l}\text { Median } \\
\text { (min-max) }\end{array}$ & $\begin{array}{l}\text { Median } \\
\text { (min-max) }\end{array}$ & \\
\hline $\begin{array}{l}\text { Pumice } \\
\text { flour }\end{array}$ & $\begin{array}{l}0.226 \\
(0.145-0.341)\end{array}$ & $\begin{array}{l}0.213 \\
(0.145-0.371)\end{array}$ & $\begin{array}{l}0.439^{\mathrm{a}} \\
(0.199-0.808)\end{array}$ & $0.000^{*}$ \\
\hline $\begin{array}{l}\text { Prophy } \\
\text { paste }\end{array}$ & $\begin{array}{l}0.208 \\
(0.156-0.274)\end{array}$ & $\begin{array}{l}0.212 \\
(0.155-0.256)\end{array}$ & $\begin{array}{l}0.329^{\mathrm{a}} \\
(0.188-0.567)\end{array}$ & $0.013^{*}$ \\
\hline $\begin{array}{l}\text { Air } \\
\text { abrasion }\end{array}$ & $\begin{array}{l}0.214 \\
(0.140-0.321)\end{array}$ & $\begin{array}{l}0.192^{\mathrm{a}} \\
(0.155-0.187)\end{array}$ & $\begin{array}{l}0.241^{\mathrm{A}} \\
(0.133-0.667)\end{array}$ & $0.004^{*}$ \\
\hline $\mathbf{p}$ & 0.530 & 0.131 & $0.002^{*}$ & \\
\hline
\end{tabular}

BL: Baseline, AIM: After immersion. * a significant difference $(p<0.05)$. ${ }^{a}$ significantly different from other groups in each row, and ${ }^{A}$ significantly different from other groups in each column $(p<0.05)$.

In Group I, Ra values were diminished after polishing for 15 seconds with PF, PP and AA; however, only significant difference was detected in PF group $(p=0.016)$. Intergroup comparison of Ra values showed no statistically significant difference ( $p=0.393)$. In Group II, surface roughness values were similar after coffee immersion (Table 2). When $15 \mathrm{sec}$ polishing were performed, surface roughness values were significantly different when compared to baseline in PF, PP and AA groups $(p<0.05$, Table 2$)$. The Kruskal-Wallis test exhibited significant difference for intergroup roughness comparison $(p=0.002)$. When pairwise comparisons were evaluated, Group AA showed significantly lower values when compared to PF ( $p=0.0007)$; and when compared to PP $(p=0.012)$. On the other hand, Group PF and PP showed similar values $(p>0.05)$.

\subsection{Color stability}

At baseline measurements, no significant differences were found among PF, PP and AA in terms of color values in both Group I and II ( $p>0.05)$. Table 3 exhibits the medians (minmax) of the color change for Group I and II.

In Group I, no statistically significant difference was detected between PF, PP and AA in terms of color change after polishing ( $p=0.093)$. In Group II, statistically significant differences were 
detected between treatment modalities in both comparisons of baseline - after immersion ( $p=0.009)$ and after immersion - after polishing ( $p=0.003$ ) (Table 3). In Group II, the highest median $\Delta \mathrm{E}$ value was detected in PP group, demonstrating more color change. Representative SEM images of enamel surfaces for each group are shown in Figure 1.

Table 3. Comparison of the Color Change Values Within and Among Different Polishing Protocols for Group I and II.

\begin{tabular}{|c|c|c|c|c|c|}
\hline \multirow[t]{3}{*}{ Subgroups } & Group I & \multirow[t]{3}{*}{ Subgroups } & \multicolumn{2}{|c|}{ Group II } & \multirow[t]{3}{*}{$p$} \\
\hline & $\begin{array}{l}\text { Baseline- } \\
\text { Post } \\
\text { polishing } \Delta E\end{array}$ & & $\begin{array}{l}\text { Baseline-After } \\
\text { immersion } \Delta \mathrm{E}\end{array}$ & $\begin{array}{c}\text { After } \\
\text { immersion- } \\
\text { Post } \\
\text { polishing } \Delta \mathrm{E}\end{array}$ & \\
\hline & $\begin{array}{c}\text { Median } \\
\text { (min-max) }\end{array}$ & & $\begin{array}{c}\text { Median } \\
\text { (min-max) }\end{array}$ & (min-max) & \\
\hline \begin{tabular}{|l} 
Pumice \\
flour
\end{tabular} & $\begin{array}{c}6.898 \\
(1.980-18.77)\end{array}$ & $\begin{array}{l}\text { Pumice } \\
\text { flour }\end{array}$ & $\begin{array}{c}24.23 \\
(9.414-50.39)\end{array}$ & $\begin{array}{c}6.352^{\mathrm{A}} \\
(1.552-10.66)\end{array}$ & $0.037^{*}$ \\
\hline \begin{tabular}{|l} 
Prophy \\
paste
\end{tabular} & $\begin{array}{c}5.522 \\
(2.602-9.032)\end{array}$ & $\begin{array}{l}\text { Prophy } \\
\text { paste }\end{array}$ & $\begin{array}{c}30.99 \\
(21.12-50.69)\end{array}$ & $\begin{array}{c}19.11^{\mathrm{B}} \\
(3.775-50.84)\end{array}$ & $0.001^{*}$ \\
\hline Air abrasion & $\begin{array}{c}8.343 \\
(2.022-13.75) \\
\end{array}$ & Air abrasion & $\begin{array}{c}25.51 \\
(9.696-45.23) \\
\end{array}$ & $\begin{array}{c}4.953^{\mathrm{A}} \\
(1.136-11.66)\end{array}$ & $0.003^{*}$ \\
\hline$p$ & 0.093 & $p$ & 0.091 & $0.002 *$ & \\
\hline
\end{tabular}

* a significant difference ( $p<0.05)$, and different superscript upper case letters indicate significant differences for Group II ( $p<0.05)$
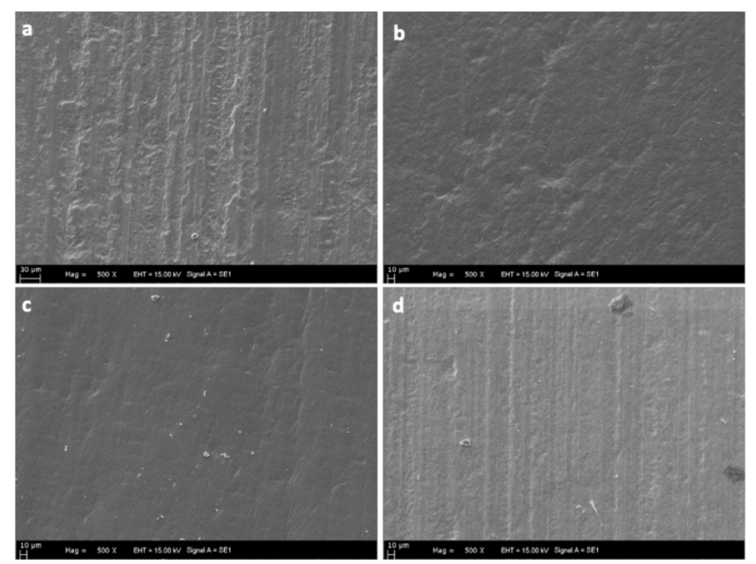

Figure 1. Representative SEM images, magnification=500x: (a) untouched enamel; (b) enamel surface polished with pumice flour; (c) enamel surface polished with prophy paste; (d) enamel surface polished with air abrasion
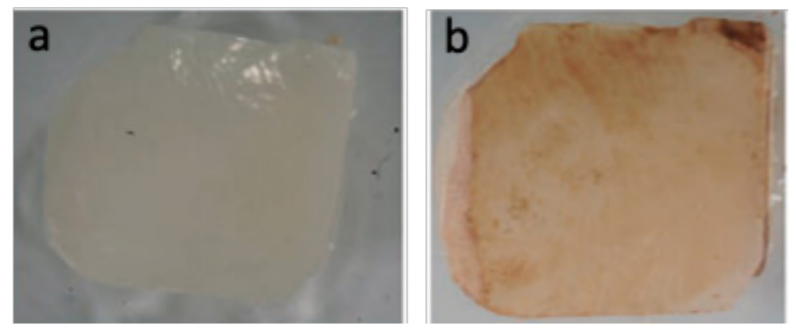

Figure 2. Representative images of specimens at baseline (a) and after immersion (b)

\section{DISCUSSION}

The main purpose of polishing, which is an integral part of clinical practice, is to remove the plaque and stains on the enamel surface to provide a surface as smooth as possible. It has been reported that scaling alone is not sufficient to reduce the surface roughness, but can be achieved by polishing afterwards (16). Moreover, there is a widespread debate about whether the tooth surface should be polished or not. Some studies suggested that polishing removes plaque and reduces bacterial colonization, resulting in a smooth tooth surface $(17,18)$. The results of the present study revealed alteration of the enamel surface with all the prophylactic methods applied. This outcome was assessed through an evaluation of the surface roughness and a scanning electron microscopy examination. On the other hand, the first null hypothesis that there would be no difference between the tested polishing systems in terms of the effect on enamel surface roughness and color change has to be accepted. Following the polishing procedure, no statistically significant difference was detected between PF, PP and AA in terms of surface roughness and color change.

Even though polishing with rubber cup and paste is the most common method, air-powder polishing devices are also becoming popular. It is believed that surfaces that rubber cup cannot reach are achieved in this way, but their actual effectiveness in smoothing the enamel surface remains controversial (19). In a study conducted by Galloway and Pashley (20), they concluded that air-polishing devices have sufficient stain removal ability. Still, their abrasive effect on enamel was not as much as applying pumice flour with a rubber cup. On the other hand, several studies $(9,21,22)$ reported that air-polishing increased the surface roughness. It has been suggested that this may be due to the shape of the sodium bicarbonate powder particle and the highpressure during application.

Sodium bicarbonate has a particle area of approximately $0.037496353 \mathrm{~mm}^{2} / 74 \mathrm{mcm}$ and the Mohs' scale hardness number of 2.5 , which is low in comparison to pumice [67], and as well as enamel [5-6]. The shape of sodium bicarbonate particles has been shown to have irregular and sharp edges (23), eroding the particles more and causing roughness on the tooth surface. It has been previously shown that increasing pressure causes more wear and roughness, leading to tooth surface loss (24). Air polisher is typically used with an air setting of $80 \mathrm{psi}$, while the pressure for bristle brush and rubber cup application is approximately 20 psi (25). Therefore, it can be interpreted that the air-polishing device should be used carefully.

According to the findings of the present study, polishing procedures reduced the surface roughness in all samples of Group I; however, no statistically significant difference was detected among PF, PP and AA $(p=0.393)$. Moreover, only polishing with rubber cup and pumice flour for 15 seconds significantly affected the enamel surface roughness. In a scanning electron microscopy (SEM) study, the authors evaluated the efficiency of 3 different polishing methods 
on enamel and cementum (26). According to their results, polishing with a rubber cup and polishing paste was more effective than polishing with a bristle brush or air polisher in obtaining a smooth enamel surface. The difference in roughness findings of polishing systems in the literature may be related to different value ranges for application time, speed and application pressure. For example, while the rpm value applied for speed in various studies ranged from 1000 rpm to $5826 \mathrm{rpm}$, the application time varied from 5 seconds to 60 seconds and the application pressure could be used between $150 \mathrm{~g}$ and $450 \mathrm{~g}$ (27-29).

In the present study, a coffee solution was used as a coloring agent because it is a frequently consumed beverage in daily life, with reference to previous studies that created artificial coloring $(14,30,31)$. Pigmentation of teeth with coffee or other beverages could cause some alterations to enamel and dentin tissues. The substances responsible for causing tooth stains in coffee solution are known as tannins which are polyphenol structures such as tannic acid, gallic acid, catechins and leucoanthocyanins. In an in vitro study conducted by Singh and Aggarwal (32), they found that coffee could change the opalescence color of teeth. On the other hand, coffee has the potential to cause erosion, but its mechanism is not fully understood $(33,34)$. However, it can be assumed that coffee deposition can cause fine abrasive effects on teeth by changing the enamel composition. Erosion is a progressive localized loss of major element components of enamel by the effect of acid or chelation (13). In agreement with the literature, following coffee immersion, the difference among groups was statistically significant for both parameters. Therefore, the second null hypothesis that different polishing systems would have no influence on the roughness of the enamel surface and the color change after exposure to coffee has to be rejected.

In general, coffee has been shown to contain a $\mathrm{pH}$ around 5.8 (35). Moreover, decalcification that can occur on the enamel surface is mainly associated with erosion caused by acidity. Manno et al. evaluated enamel staining by coffee using spectroscopy and scanning electron microscopy and reported that coffee caused a loss in calcium and phosphates, the main elements of hydroxyapatite (36). Moreover, it has been reported that the change in the color of teeth is due to the high concentration of metals contained in coffee. In another SEM study, the effects of soft drinks such as coffee on etched and sealed enamel were investigated (37). The authors stated that demineralization occurs when etched regions of the enamel are exposed to coffee. According to our findings, the roughness values of specimens did not differ significantly after immersion in coffee solution. This result of the study may be due to the fact that the immersion time in coffee coincides with the 2-months coffee consumption and a possible erosion did not make a significant difference in roughness device measurements. On the other hand, after immersion and $15 \mathrm{sec}$ polishing, Ra values for all groups significantly increased. It is noteworthy that the roughness values of the samples subjected to only the polishing procedure decreased, while the roughness values of the samples immersed in coffee solution increased after polishing. As mentioned in the above studies, the abrasive potential of the polishing procedures may have arisen, possibly because coffee made the enamel surfaces more vulnerable to damage. Therefore, clinicians may need to pay attention to factors such as handpiece speed or pressure in the polishing process of patients who consume too much coffee.

The result of this study indicated that all the tested polishing systems were effective on removing stains from the teeth surfaces as they all showed $\Delta \mathrm{E}$ values above 3.3 , which is accepted as the threshold value for a clinically significant color change (38). There are different methods to detect color; moreover, the most preferred one in clinical practice is visual color selection. On the other hand, visual color selection does not provide reliable results for scientific research because of various factors such as the experience of the person who makes the determination, ambient light and lighting, the wall color of the room. In order to detect tooth color and discoloration, spectrophotometers are mostly preferred for scientific research, so that in the present study, the color measurements obtained with the spectrophotometer were evaluated based on the International Commission of Illumination (CIE) color system.

In Group I, $\Delta \mathrm{E}$ values ranged from 3.4 to 18.7 following polishing and no statistically significant difference was observed among groups in terms of color change. Based on this finding, the following comment can be made that all three polishing methods tested could clean superficial stains at a noticeable level. Camboni and others (39) compared the tooth surface following air-polishing and rubber cup polishing with several different pastes using SEM analysis. They reported that air-polishing was able to clean more deeply without any damage to the enamel compared to polishing pastes with rubber cup. In agreement with this study, the surface roughness values of specimens exposed to air-polishing were lower than other groups, for both groups (Group I and II) of this study. On the other hand, polishing with rubber cup and prophy paste following coffee immersion showed higher color change compared to other polishing protocols. This interesting result may be related to the fact that the rougher surface of the enamel which was subjected to immersion and polishing with rubber cup and pumice flour, may be associated with a minimal surface loss and may have caused more reflection of the dentin color. Therefore, prophy paste may have been the method that removed coffee stains better than other tested polishing methods.

In the present study, bovine teeth were preferred because of the larger flat areas that could accommodate the tip of the profilometer and spectrophotometer handpiece. Moreover, bovine teeth are used routinely as an alternative to human teeth in in vitro studies $(40,41)$. Like other in vitro studies, clinical difficulties arising from the oral environment could not be mimicked exactly and is one of the limitations of the study. Especially saliva, which is a natural part of the oral environment and may buffer the possible erosive effect of 
coffee, was not used in the study. Therefore, these results need to be supported by more studies.

\section{CONCLUSION}

According to the results of the present study, one can suggest that the statistically significant smoothest surface was achieved after polishing with rubber cup and PF for 15 sec; however, after coffee immersion teeth surfaces were more prone to erosion and became rough in all polishing protocols and the roughest surface was in PF group. In all study groups visible clinical success was achieved in terms of color; therefore, dental clinicians should prefer PP in clinical practice due to the less abrasive and sufficient color change properties.

\section{Disclosure Statement}

The authors do not have any financial interest in the companies whose materials are included in this article.

\section{Acknowledgement}

This study was carried out within the scope of the International Dental Research Program (IDRP). This study was presented in IADR General Session, 2020. Washington D.C. USA

\section{Conflict of Interest}

The authors declare that they have no conflict of interest.

\section{REFERENCES}

[1] Barnes CM. The science of polishing. Dimen Dent Hyg 2009;7:1822.

[2] Patil SS, Rakhewar PS, Limaye PS, Chaudhari NP. A comparative evaluation of plaque-removing efficacy of air polishing and rubber-cup, bristle brush with paste polishing on oral hygiene status: A clinical study. J Int Soc Prev Community Dent 2015;5(6):457-462.

[3] Kimyai S, Mohammadi N, Alizadeh Oskoee P, PournaghiAzar F, Ebrahimi Chararrom ME, Amini M. Effect of different prophylaxis methods on microleakage of microfilled composite restorations. J Dent Res Dent Clin Dent Prospects 2012;6(2):65-69.

[4] Kimyai S, Savadi-Oskoee S, Ajami AA, Sadr A, Asdagh S. Effect of three prophylaxis methods on surface roughness of giomer. Med Oral Patol Oral Cir Bucal 2011;16(1):e110-4.

[5] Petersilka GJ, Bell M, Haberlein I, Mehl A, Hickel R, Flemmig TF. In vitro evaluation of novel low abrasive air polishing powders. J Clin Periodontol 2003;30(1):9-13.

[6] Roulet JF, Roulet-Mehrens TK. The surface roughness of restorative materials and dental tissues after polishing with prophylaxis and polishing pastes. J Periodontol 1982;53(4):257266.

[7] Badersten A, Nilveus R, Egelberg J. Effect of nonsurgical periodontal therapy. II. Severely advanced periodontitis. J Clin Periodontol 1984;11(1):63-76.
[8] Salami D, Luz MA. Effect of prophylactic treatments on the superficial roughness of dental tissues and of two esthetic restorative materials. Pesqui Odontol Bras 2003;17(1):63-68.

[9] Castanho GM, Arana-Chavez VE, Fava M. Roughness of human enamel surface submitted to different prophylaxis methods. J Clin Pediatr Dent 2008;32(4):299-303.

[10] Guler AU, Yilmaz F, Kulunk T, Guler E, Kurt S. Effects of different drinks on stainability of resin composite provisional restorative materials. J Prosthet Dent 2005;94(2):118-124.

[11] Azer SS, Hague AL, Johnston WM. Effect of $\mathrm{pH}$ on tooth discoloration from food colorant in vitro. J Dent 2010;38 Suppl 2:e106-109.

[12] Klein OD, Duverger O, Shaw W, et al. Meeting report: a hard look at the state of enamel research. Int J Oral Sci 2017;9(11):e3.

[13] Karda B, Jindal R, Mahajan S, Sandhu S, Sharma S, Kaur R. To Analyse the Erosive Potential of Commercially Available Drinks on Dental Enamel and Various Tooth Coloured Restorative Materials - An In-vitro Study. J Clin Diagn Res 2016;10(5):ZC117-21

[14] Bazzi JZ, Bindo MJ, Rached RN, Mazur RF, Vieira S, de Souza $E M$. The effect of at-home bleaching and toothbrushing on removal of coffee and cigarette smoke stains and color stability of enamel. J Am Dent Assoc 2012;143(5):e1-7.

[15] Hattab FN, Qudeimat MA, al-Rimawi HS. Dental discoloration: an overview. J Esthet Dent 1999;11(6):291-310.

[16] Kaldahl WB, Kalkwarf KL, Patil KD, Molvar MP, Dyer JK. Longterm evaluation of periodontal therapy: I. Response to 4 therapeutic modalities. J Periodontol 1996;67(2):93-102.

[17] Jana A, Chakraborty A, Pal TK, Datta S. Profilometric analysis of root surfaces after using various polishing agents. J Indian Soc Periodontol 2016;20(1):22-27.

[18] Waring MB, Newman SM, Lefcoe DL. A comparison of engine polishing and toothbrushing in minimizing dental plaque reaccumulation. Dent Hyg (Chic) 1982;56(12):25-30.

[19] Madan C, Bains R, Bains VK. Tooth polishing: Relevance in present day periodontal practice. J Indian Soc Periodontol 2009;13(1):58-59.

[20] Galloway SE, Pashley DH. Rate of removal of root structure by the use of the Prophy-Jet device. J Periodontol 1987;58(7):464469.

[21] Agger MS, Horsted-Bindslev P, Hovgaard O. Abrasiveness of an air-powder polishing system on root surfaces in vitro. Quintessence Int 2001;32(5):407-411.

[22] Sahrmann P, Ronay V, Schmidlin PR, Attin T, Paque F. Threedimensional defect evaluation of air polishing on extracted human roots. J Periodontol 2014;85(8):1107-1114.

[23] Petersilka GJ, Bell M, Mehl A, Hickel R, Flemmig TF. Root defects following air polishing. J Clin Periodontol 2003;30(2):165-170.

[24] Jost-Brinkmann PG. The influence of air polishers on tooth enamel. An in-vitro study. J Orofac Orthop 1998;59(1):1-16.

[25] Francis B, Barnes BC. Cosmetic and therapeutic polishing. In: Daniel SJ HS, Wilder R., editor. Mosby's Dental Hygiene: Concepts, Cases and Competencies Missouri: Elsevier; 2008.p.600-622.

[26] Chowdhary Z, Mohan R. Efficiency of three different polishing methods on enamel and cementum: A scanning electron microscope study. J Indian Soc Periodontol 2018;22(1):18-24.

[27] Putt MS, Kleber CJ, Muhler JC. Enamel polish and abrasion by prophylaxis pastes. Dent Hyg (Chic) 1982;56(9):38, 40-43. 
[28] Stookey GK. In vitro estimates of enamel and dentin abrasion associated with a prophylaxis. J Dent Res 1978;57(1):36.

[29] Zampa ST, Green E. Effect of polishing agents on root roughness. J Periodontol 1972;43(2):125-126.

[30] Darabi F, Seyed-Monir A, Mihandoust S, Maleki D. The effect of preheating of composite resin on its color stability after immersion in tea and coffee solutions: An in-vitro study. J Clin Exp Dent 2019;11(12):e1151-e6.

[31] Rezende M, Loguercio AD, Reis A, Kossatz S. Clinical effects of exposure to coffee during at-home vital bleaching. Oper Dent 2013;38(6):E229-36.

[32] Singh SV, Aggarwal P. Effect of tea, coffee and turmeric solutions on the colour of denture base acrylic resin: an in vitro study. J Indian Prosthodont Soc 2012;12(3):149-153.

[33] Ren JS, Freedman ND, Kamangar F, Dawsey SM, Hollenbeck AR, Schatzkin A, Abnet CC. Tea, coffee, carbonated soft drinks and upper gastrointestinal tract cancer risk in a large United States prospective cohort study. Eur J Cancer 2010;46(10):1873-1881.

[34] Dugmore CR, Rock WP. A multifactorial analysis of factors associated with dental erosion. Br Dent J 2004;196(5):283-286

[35] Lussi A, Megert B, Shellis RP, Wang X. Analysis of the erosive effect of different dietary substances and medications. $\mathrm{Br} \mathrm{J}$ Nutr 2012;107(2):252-262.
[36] Manno SHC, Manno FAM, Ahmed I, Ahmed R, Shu L, Li L, Xu S, Xie F, Li VW, Ho J, Cheng SH, Lau C. Spectroscopic examination of enamel staining by coffee indicates dentin erosion by sequestration of elements. Talanta 2018;189:550-559.

[37] Dincer B, Hazar S, Sen BH. Scanning electron microscope study of the effects of soft drinks on etched and sealed enamel. Am J Orthod Dentofacial Orthop 2002;122(2):135-141.

[38] Kiomars N, Azarpour P, Mirzaei M, Hashemi Kamangar SS, Kharazifard MJ, Chiniforush N. Evaluation of the Diode laser $(810 \mathrm{~nm}, 980 \mathrm{~nm})$ on color change of teeth after external bleaching. Laser Ther 2016;25(4):267-272.

[39] Camboni S, Donnet M. Tooth Surface Comparison after Air Polishing and Rubber Cup: A Scanning Electron Microscopy Study. J Clin Dent 2016;27(1):13-18.

[40] Liporoni PC, Souto CM, Pazinatto RB, Cesar IC, de Rego MA, Mathias P, Cavalli C. Enamel susceptibility to coffee and red wine staining at different intervals elapsed from bleaching: a photoreflectance spectrophotometry analysis. Photomed Laser Surg 2010;28 Suppl 2:S105-109.

[41] Attia ML, Aguiar FH, Mathias P, Ambrosano GM, Fontes CM, Liporoni CM. The effect of coffee solution on tooth color during home bleaching applications. Am J Dent 2009;22(3):175-179. 